\title{
Supporting Information for \\ Truncation, Deamidation, and Oxidation of Histone H2B in Cells Cultured with Nickel(II)
}

Aldona A. Karaczyn, Filip Golebiowski, and Kazimierz S. Kasprzak*

Laboratory of Comparative Carcinogenesis, National Cancer Institute at Frederick, Frederick, Maryland 21702 


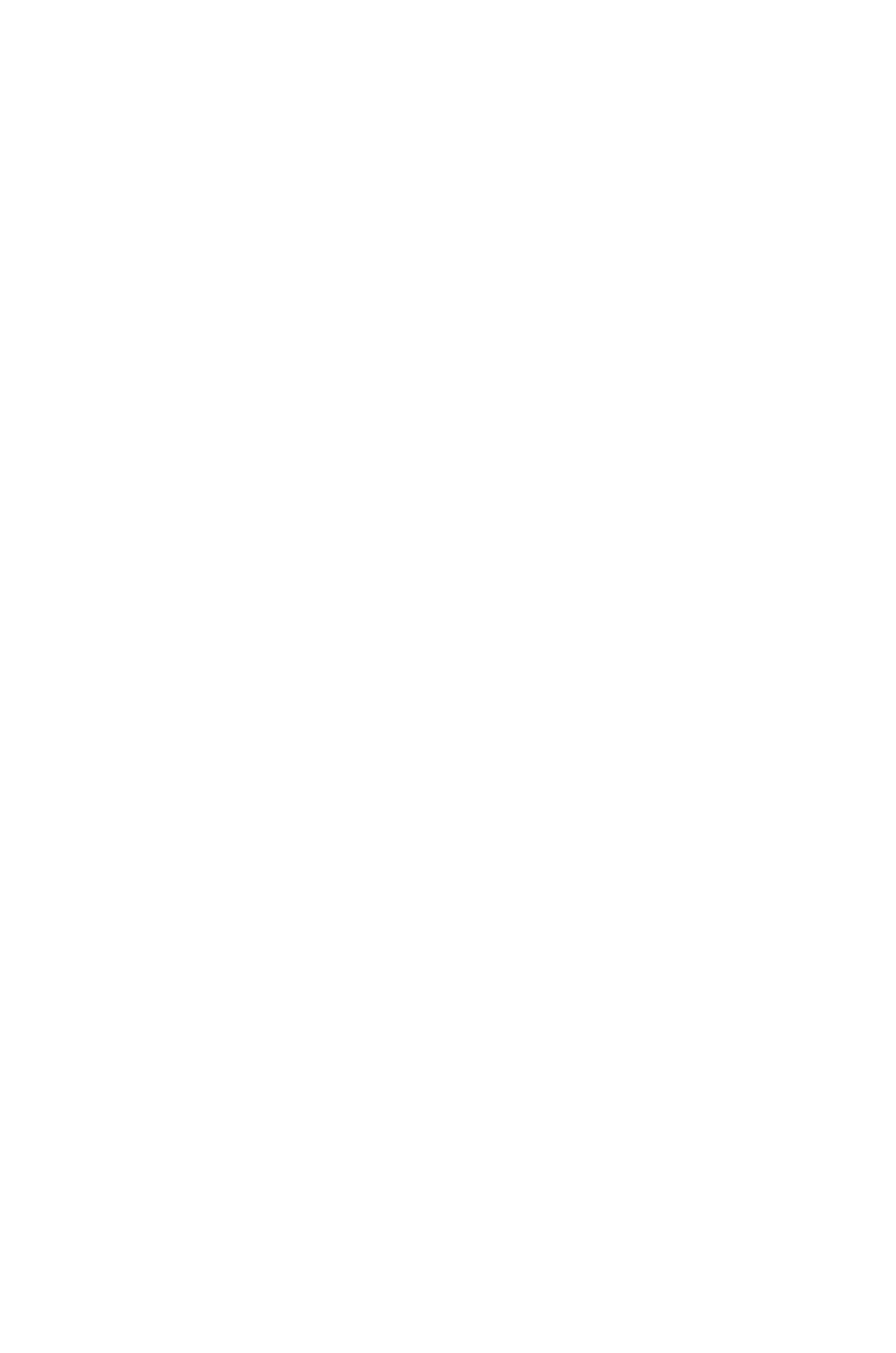

Figure 1S. Cell proliferation rates expressed in number of cells per well at days 3 and 5 as compared with day 0 when the metals were added to the cultures. Numbers under the 
bars indicate metal concentrations, $\mu \mathrm{M}$. Cells were seeded at day -1 into wells of 96-well $12.5 \times 85-\mathrm{cm}$ plastic plates and grown for one day in the same metal-free media as those used for the flask cultures (see Materials and Methods). The metals were added on day 0 into two wells per each metal concentration/time point. The five-day cultures had their metal-containing or metal-free (controls) media changed at day 3 . The harvested wells were washed twice with PBS and the adherent cells were collected in respective culture media with the help of trypsin, and counted in a hemocytometer. 



\section{FACS Profiles}

\section{NRK-52E Cells, 5-day Treatment with Ni(II)}

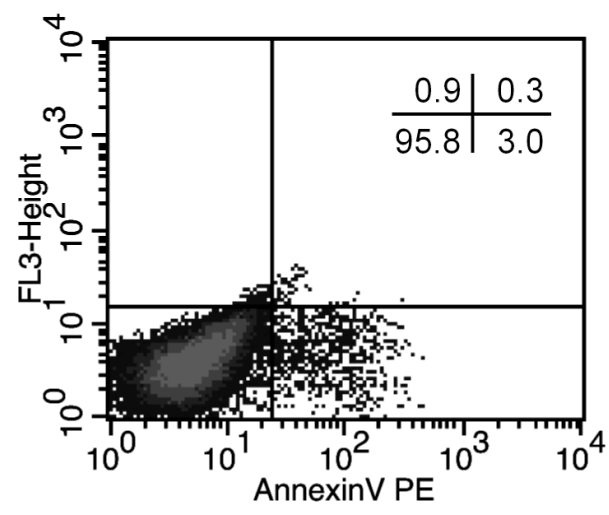

Untreated, Annexin only

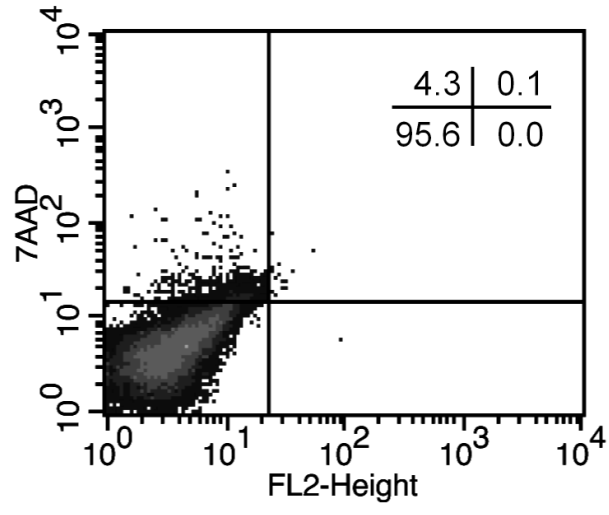

Untreated, 7AAD only

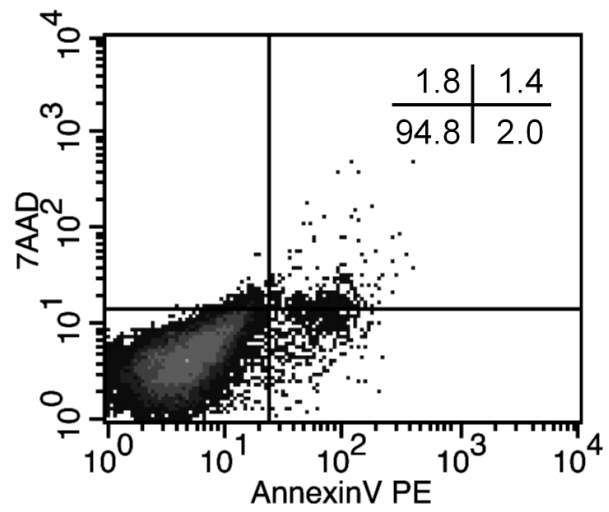

Untreated, both markers

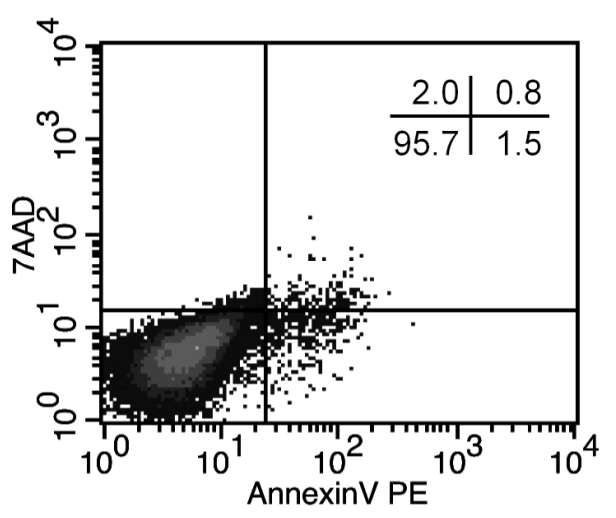

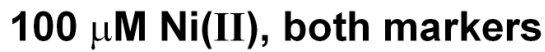

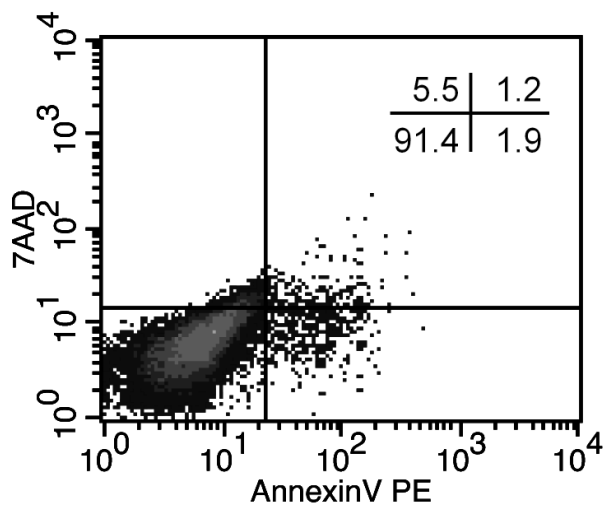

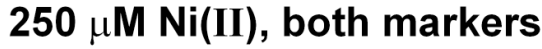

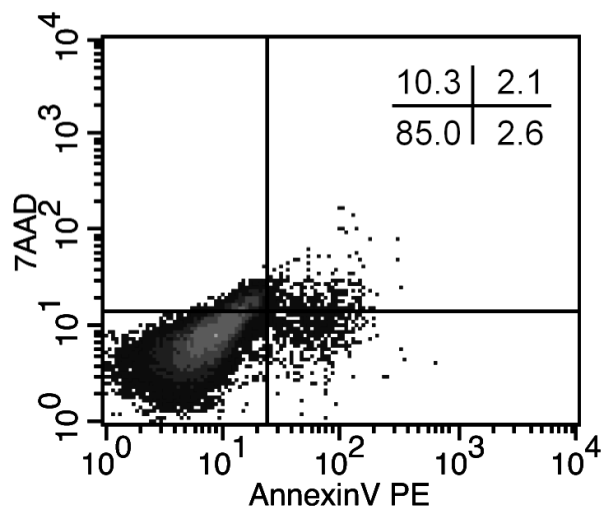

$500 \mu \mathrm{M} \mathrm{Ni}(\mathrm{II})$, both markers 
FACS Profiles

NRK-52E Cells, 6-hr Treatment with Staurosporine
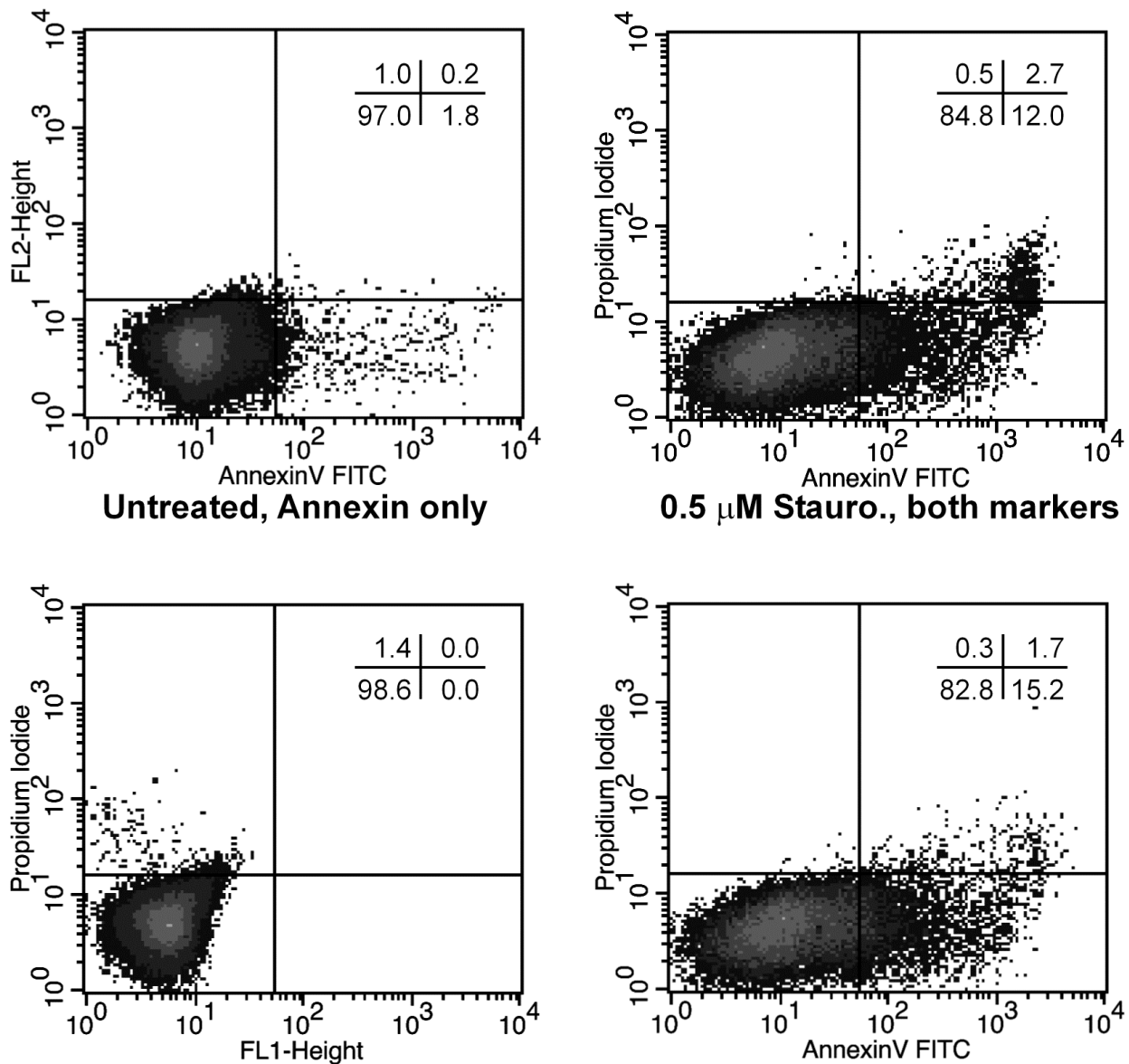

Untreated, PI only
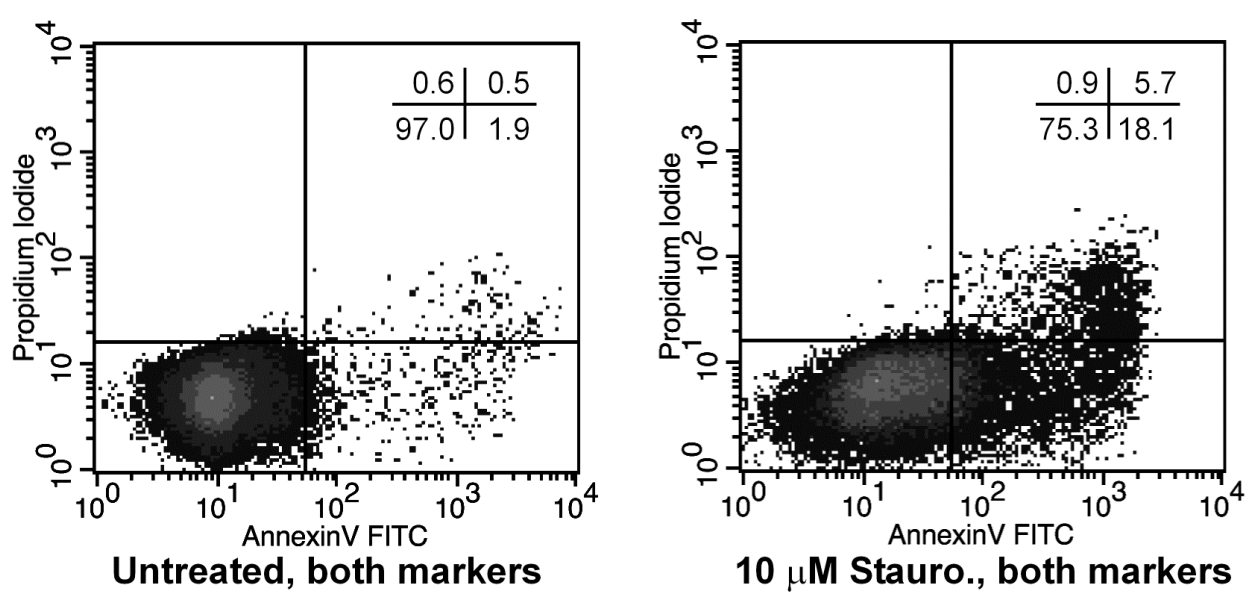
Figure 2S. FACS profiles of NRK-52E cells cultured for 3 and 5 days with $0-500 \mu \mathrm{M}$ $\mathrm{Ni}$ (II) concentrations, or for 6 hours with $0-10 \mu \mathrm{M}$ of staurosporine. The distribution of cells, in percentages, is given in the insets for each quadrant, respectively. 